\title{
A formação de clusters criativos e a coexistência nas cidades contemporâneas
}

The formation of creative clusters and the coexistence in contemporary cities

Christianne Soares Falcão - Universidade Católica de Pernambuco I Recife I PE I Brasil | christianne.falcao@unicap.br (1) 0000-0002-8227-0412

Alberico Paes Barreto Barros - Universidade Católica de Pernambuco I Recife I Pernambuco I Brasil I alberico.paesbarreto@unicap.br 0000-0003-1103-1091

Gabriela Viana Leão - Universidade Católica de Pernambuco I Recife I Pernambuco I Brasil I gabrielavianaleao@gmail.com 00000-0003-0459-8030

Resumo: Uma cidade criativa é regida, entre outras coisas, por conexões e, por isso, a coexistência se torna um fator relevante na sua dinâmica. O artigo, ora apresentado, tem como objetivo lançar um olhar para as mudanças sociais e econômicas ocorridas na sociedade contemporânea, nas quais o foco nas atividades industriais foi deslocado para as atividades intensivas em conhecimento. Dessa forma, procura-se compreender o contexto de formação de uma nova economia cuja cadeia produtiva se estabelece sobre criatividade e inovação. Essa nova economia, na qual o capital tem base intelectual, fundamenta-se no indivíduo, na formação de redes sociais e na troca de conhecimentos, levando ao surgimento de uma estrutura econômica baseada na concentração geográfica de empresas inter-relacionadas com foco em produtos culturais e criativos, que estabelecem a coexistência no ambiente urbano onde se instalam, e a consequente transformação das cidades: os Clusters Criativos.

Palavras-chave: Economia criativa. Cidades criativas. Clusters.

Abstract: A creative city is governed, among other things, by connections and, therefore, the coexistence becomes a relevant factor in its dynamics. The present article aims to look at the social and economic changes that have taken place in contemporary society, in which the focus on industrial activities was shifted to intensive knowledge activities. In this way, it seeks to understand the context of formation of a new economy whose productive chain is established on creativity and innovation. This new economy, in which capital has an intellectual base, is based on the individual, on social networks formation and on knowledge exchange, leading to the emergence of an economic structure based on the geographic concentration of interrelated companies focusing on cultural and creative products that establish the coexistence in the urban environment where they are installed and the consequent transformation of cities: Creative Clusters.

Keywords: Creative economy. Creative cities. Clusters.

http://doi.org/10.22484/2318-5694.2019v7n14p163-178

Recebido em novembro 2018 - Aprovado em fevereiro 2019 


\section{Introdução}

$O$ entendimento de que o mundo estava se transformando rapidamente a partir do início da década de 1970, resultou em muitas reflexões nos diversos âmbitos econômicos, culturais, sociais e políticos da sociedade. Nesse ínterim, uma confluência de diversos fatores impulsionou a formação de uma nova dinâmica de processos e modelos sociais desencadeados pela globalização, pelas novas mídias e, sobretudo, pela valorização do conhecimento como ativo econômico (REIS, 2011).

No que tange à globalização, sob um ponto de vista econômico, pode ser caracterizada por uma maior acessibilidade às transações, à mobilidade dos ativos financeiros e à conjugação da fragmentação das cadeias produtivas em escala planetária, oferecendo oportunidades de produção, distribuição e consumo de bens e serviços criativos a mercados antes inviáveis. (REIS, 2011, p. 3).

Para Castells (2009), as sociedades agora são "auto construídas" pelas redes. As mudanças dessa nova sociedade estão baseadas na "transformação do espaço, do tempo, do trabalho, da cultura [...] e na

globalização como a rede seletiva de lugares e processos pelo planeta" (CASTELLS, 2009, p. 37). Para ele, a organização em redes globais passou a moldar e controlar a vida humana, a partir de então, com base na dispersão mundial das tecnologias de informação e comunicação. A nova economia passou a ter a inovação como fonte de crescimento da produtividade, modificando as relações de poder, que passaram a operar com base em dois sentidos: a construção em torno da articulação entre o local e o global; a organização em torno de redes e não de unidades (CASTELLS, 2009).

Estabelece-se, então, um novo paradigma de desenvolvimento que aproxima estas diversas atividades, apontando a criatividade, a inovação e o acesso à informação como vetores para o desenvolvimento mundial. 
De fato, os avanços tecnológicos e as redes em massa (internet) causaram um grande impacto nas atividades industriais. Esse novo sistema baseado em redes apresenta, entre outros, um fator determinante para a evolução dessa nova economia, a constituição de uma economia de redes de informação com base na colaboração (SILVEIRA; BENKLER, 2007). Conforme aponta Landry (2013), quando o conhecimento é compartilhado e aplicado tende a um maior crescimento, em vez de um esgotamento, e faz com que a economia mude "de um viés de escassez para uma abundância em potencial" (LANDRY, 2013, p. 20).

Com base nesta mudança de olhar apontado nos setores econômicos e sociais, um novo debate também se estabeleceu quanto à transformação das cidades como um local propício para o desenvolvimento da criatividade de seus habitantes. Corroborando com esse entendimento, Falcão et al. (2018) apontam:

[...] com a transformação iminente da economia, a cidade como cenário propício para a criação de um meio social, precisa ser planejada para oferecer condições às pessoas pensarem e agirem com imaginação. Uma cidade criativa provoca estímulos para a construção de uma cultura de participação com base na criatividade (p. 73).

Neste cenário, o presente artigo tem como abordagem estabelecer o debate da importância de um polo tecnológico da indústria criativa (cluster) para atender às necessidade da sociedade global nas cidades contemporâneas, propiciando um ambiente criativo e de coexistência.

\section{A Indústria Criativa e a Cidade Criativa}

A partir do momento em que a criatividade se transforma em um instrumento fundamental para o desenvolvimento de mercados, a busca por transformações passou a ganhar espaço. As mudanças na construção dos valores, segundo Faustino (2013), se baseiam neste conceito, e as indústrias criativas assumem um importante papel neste contexto por 


\title{
tríade
}

proporcionarem a democratização da cultura e da arte, como também por impulsionarem o desenvolvimento da economia.

O debate acerca das indústrias criativas vem sendo desenvolvido nas diferentes áreas do conhecimento na busca por respostas aos seus respectivos questionamentos que, até então, não foram conclusivos devido à grande extensão e subjetividade da temática em questão. Faustino ressalta a extrema relevância para a diversidade cultural, inclusão social e desenvolvimento humano das indústrias criativas ao descrever:

\begin{abstract}
Constituídas por artistas independentes, microempresas e algumas das maiores multinacionais do mundo, as indústrias criativas ocupam lugar entre os setores mais dinâmicos do comércio mundial. Os produtos culturais e criativos são, hoje, encarados como recursos tão valiosos como foram o ferro e o carvão na era industrial. A diferença é que estes - ferro e carvão - podiam ser encontrados no subsolo, enquanto os produtos culturais e criativos decorrem da capacidade intelectual e criativa do ser humano, da sua prática social, da linguagem do cotidiano e dos códigos de moda. Pensar que a ciência, indústria e cultura são setores ou atividades distintas - e sem possibilidade de se relacionarem - é uma ideia obsoleta e manifesta um grande constrangimento ao progresso da sociedade e ao desenvolvimento dos negócios. No contexto da economia criativa não existem diferenças entre a criatividade do cientista, artista ou empresário - ou seja: a atitude de criar coexiste com a necessidade de comercializar (FAUSTINO, 2013, p. 36).
\end{abstract}

Faustino aponta também que, na data de publicação do relatório da UNESCO (2006), nos países industrializados, quase um terço dos trabalhadores estavam nas diversas áreas do conhecimento do setor criativo, concluindo que "direta ou indiretamente, todos os negócios recorrem à cultura e à criatividade" (FAUSTINO, 2013, p. 36).

Nesta direção, é preciso também acrescentar o fato de que é nas cidades onde são desenvolvidas relações econômicas e humanas, surgindo então o conceito de Cidades Criativas, com ênfase na importância da criatividade para a cidade e sua economia (REIS, 2011).

No entanto, para explicar o que é uma cidade criativa, é preciso, primeiro, recorrer ao conceito que torna uma determinada localidade criativa e também à história do desenvolvimento das urbes. De acordo com 
a escritora Sposito (1988), ao contrário do que se pode supor, as cidades não têm suas origens explicadas "essencialmente pelo econômico, mas também pelo social e pelo político" (p. 14). Isso quer dizer, em outras palavras, que a origem dos conglomerados urbanos não está somente na produção de bens mas, também na apropriação dos espaços.

Tomando de forma breve e sucinta a história do homem, na convivência social, e guardadas as devidas proporções, é possível inferir que os reis ou líderes político-religiosos surgiram como uma evolução do homem caçador. O período neolítico, após a cultura de caça, foi marcado pela estabilidade de aldeias - aglomerados de agricultores -, que se diferenciam das cidades por não terem uma configuração tão complexa, quase não apresentando a divisão do trabalho. A diferenciação que existia era de atividades femininas e masculinas ou ainda por força e idade.

Com o tempo e desenvolvimento da cultura agrícola e seleção de sementes, os agricultores começaram a produzir mais que o necessário para o próprio sustento, o que gerou o excedente alimentar. Esse excedente alimentar foi um dos fatores mais relevantes que levaram as aldeias a iniciarem uma divisão social do trabalho - o que ocasionou a formação da cidade.

Dentre algumas mudanças, o fato proporcionou um ambiente mais favorável para que alguns homens pudessem sair da atividade primária e passassem a se dedicar a outras coisas. Os mais fortes, que anteriormente eram responsáveis pela caça, passaram a desempenhar uma atividade de maior importância em governar os aldeões (SPOSITO, 1988).

Assim como a governança foi essencial na transmutação das aldeias para as cidades, é também primordial manter-se em desenvolvimento para impulsionar a inovação e o crescimento das cidades contemporâneas. E, para assim fazer, é necessário o uso da criatividade.

Conforme Landry (2008), as cidades são como seres vivos com fases de crescimento, estagnação e declínio e, para isso, faz-se necessário 
repensar o seu papel e os recursos disponíveis, bem como o funcionamento de seu planejamento urbano no momento em que o mundo atravessa mudanças dramáticas. Esta viabilidade urbana é justamente "a capacidade das cidades de se adaptar e responder a mudança das circunstâncias" (REIS, 2011, p. 34).

Para Florida (2002), o lugar desempenha um papel decisivo para a economia: talento, inovação e criatividade estão reunidos em localidades específicas e não distribuídos igualmente pelo mundo. Esta concentração crescente de talento e pessoas produtivas ao redor desses locais, torna-se cada vez mais o motor para o desenvolvimento e crescimento econômico (LEITE; AWAD, 2012).

Para tal, a dinâmica dos centros urbanos com tantas mudanças no cotidiano, pode ser compreendida a partir dos ambientes construídos que representam o modo como os espaços da cidade são organizados, dando sinais de como as práticas sociais são realizadas. Nesta circunstância, a implementação de políticas públicas, a partir da articulação entre entidades públicas e privadas, pode criar ações de reorganização deste território, de seu patrimônio e do capital humano. (FAUSTINO, 2013, p. 21).

Neste contexto, uma boa governança pode melhor conduzir as atuações e transformações na cidade, garantindo melhor coexistência entre as diversidades e gerando conexões. Para tal, é preciso a implementação das políticas públicas articuladas nos diversos setores, visto que, "sozinha, nenhuma das partes tem a capacidade de enfrentar mudanças e desafios que afetam a cidade. Nesse contexto, a melhor liderança é a relacional". (PARDO, 2011, p. 91).

Portanto, uma cidade criativa é aquela que possui um potencial de atrair as indústrias criativas e as pessoas criativas, propiciando um ambiente cultural econômico favorável. Para tal, conforme Reis e Urani (2011, p. 33), é necessário a prevalência de três elementos, inovação, conexão e cultura. 
a) Inovação. Corresponde à criatividade aplicada na solução de problemas e/ou na antecipação de oportunidades, podendo ser de ordem tecnológica, social, cultural e ambiental.

b) Conexão. Podendo ser histórica, geográfica, de governanças e de diversidades.

c) Cultura. Nas cidades criativas, a cultura aparece em quatro formas. A primeira consiste no conteúdo cultural, que são produtos, serviços, patrimônios e manifestações; a segunda como indústrias criativas, abrangendo cadeias culturais, da criação e produção e de consumo e acesso; e as duas últimas formas são agregar valor a setores tradicionais e formar um ambiente criativo.

\section{Os Clusters Criativos e a coexistência}

A coexistência, também vista como forma de conexão entre as diversidades, é um dos indicadores das cidades criativas. No entanto, é também um problema para muitas dessas urbes. De acordo com Landry (2008), "criatividade urbana é difícil de alcançar desde que isso significa trazer junto uma mistura variada de atores, agentes e grupos de interesse com variados backgrounds, aspirações, potenciais e culturas" (p. 106, tradução nossa). Isso porque, ao construir elementos que transformam um município em criativo, acontece também a gentrificação e a polarização socioeconômica. O espaço passa a atrair o que irá formar, em grande parte, a classe criativa do local: moradores de fora. A cidade começa a ser vista como um polo em que passa a atrair indústrias e talentos para prosperarem em um local que favorece esse desabrochar.

Contudo, o custo de vida aumenta com o sucesso da cidade e os antigos moradores, que não necessariamente alavancaram com a economia do local, terminam por perder espaço e poder econômico comparado às novas ofertas. Apesar de não dar para evitar o problema, há formas de 


\section{tríade}

garantir que a população local continue podendo usufruir da cidade, com boa governança e políticas públicas voltadas também para a coexistência.

A migração da classe criativa não causa apenas a gentrificação e a polarização econômica, e atua positivamente na cidade, com novas ideias e perspectivas que trazem soluções. Segundo Landry (2008), habitantes de cidades com populações singulares e homogêneas, muitas vezes acham mais difícil serem largamente criativos. "Eles podem encontrar várias soluções dentro das próprias perspectivas, mas são menos propensos a encontrar o mix de imaginação necessários para as complexidades emergentes da vida urbana" (p.111, tradução nossa).

Por esses motivos, talentos de fora são deliberadamente importados, porque a maioria das cidades discutem os problemas olhando de dentro para dentro, a partir dos próprios hábitos, tradições e cultura, e olham apenas ocasionalmente para o "mundo além". Quem vem de fora é, pelo menos inicialmente, mais livre de pressões e constrangimentos institucionais. "Eles podem trazer a virtude de renovação para a cidade, e as primeiras impressões deles são normalmente mais reveladoras e rapidamente capazes de identificar novos potenciais" (LANDRY, 2008, p. 112).

No entanto, investir apenas em talentos vindos de fora não é a solução. O equilíbrio entre imigrantes e nativos é, na verdade, a chave para a prosperidade de uma cidade criativa. É imprescindível aproveitar potencial de inteligência, aprendizagem e criatividade endógena, tanto para motivar as pessoas, quanto para criar autoconfiança e propriedade local. Essa atitude de valorização da população local promove responsabilidade, aproveita recursos em todos os níveis e gera um banco de ideias.

Neste ambiente de coexistência, o impulso para as inovações criativas requer um espaço de compartilhamento e colaboração entre as pessoas e a formação de clusters criativos está na gênese desse conceito. 
Os clusters criativos, fortalecidos com o processo de reestruturação produtiva, tendem a provocar transformações significativas no espaço urbano; o território se organiza de um novo modo, com novas demandas e funções específicas, com base na implementação destes novos arranjos produtivos (LEITE; AWAD, 2012).

Mas afinal, o que vem a ser um cluster?

O conceito de cluster já é amplamente conhecido na literatura especializada e remonta à idade média. Com a obra Principles of Economics, do economista britânico Alfred Marshall, em 1890, surgiram os primeiros estudos sobre aglomerações econômicas, cuja pauta trazia a importância da concentração geográfica no desenvolvimento econômico e social (SILVA, 2014).

Os clusters são objetos de diversas pesquisas realizadas por vários autores em diferentes contextos, que trazem definições diversas sobre seu conceito. Essa multiplicidade se explica pela presença de "[...] elementos qualitativos, como confiança, meio social e ambiente criativo, que são variáveis difíceis de medir e que possibilitam diversas interpretações" (LEITE; AWAD, 2012, p. 106).

Uma das principais personalidades, quando os conceitos dessas estruturas econômicas são abordados, é o economista norte-americano Michael Porter.

Porter define que cluster é uma concentração geográfica de empresas e instituições interconectadas em torno de um determinado setor (PORTER, 1998). Leite e Awad (2012) complementam: são estruturas econômicas ativas compostas por fornecedores de componentes, maquinário e serviços; com ampla infraestrutura especializada e boas relações com consumidores e fornecedores relacionados à sua cadeia produtiva. Ainda segundo os autores, os clusters agregam em sua composição instituições de ensino acadêmico e centros de treinamento, com a finalidade de promover educação, informação, pesquisa, treinamento especializado e suporte 


\section{tríade}

técnico, como também recebem "[...] o apoio de forças governamentais, que fomentam seu desenvolvimento na forma de incentivos e programas diversos" (LEITE; AWAD, 2012, p. 108).

Ampliando esse conceito, outros autores também trazem uma contribuição para melhor compreensão do tema:

Leite e Awad (2012, p. 109), argumentam que, além da concentração espacial de empresas, as relações de interdependência entre elas devem ser abrangentes, incluindo as comunidades científicas, associações profissionais e institutos apoiados pelo governo. Esta iniciativa propicia aos clusters desenvolver relações de cooperação que normalmente não acontecem com as empresas localizadas de forma dispersa do ponto de vista geográfico.

Faustino (2013, p. 45) aponta que "o cluster é o resultado da existência e do desenvolvimento de redes locais, que decorrem de fatores específicos de localização", cuja identificação e distinção se dá pela "[...] cooperação em atividades de inovação e aprendizagem interativa".

Flew descreve que "a perspectiva cultural e econômica da geografia tem sido importante na compreensão das indústrias criativas $[\ldots]$, no desenvolvimento geográfico de clusters, [...] e na criação de cidades e regiões num contexto econômico global" (FLEW apud FAUSTINO, 2013, p. 45).

O'Mara sugere que entre os fatores críticos necessários para implementação de um cluster, destacam-se:

i) Promover e facilitar o diálogo entre todas as partes envolvidas num determinado espaço geográfico; ii) Definir um território de implantação, gerar uma 'visão' comum e definir metas; iii) Gerar um programa, assim como uma estratégia, para implementação a médio/longo prazo; iv) Criar espaço para o estabelecimento de lideranças naturais, em cada um dos três poderes: político, empresarial e cultural;

v) Criar um movimento com uma ampla participação e envolver as universidades e centros de investigação; vi) Gerir o projeto ao longo de todo o processo de implementação, adotando metodologias eficazes de gestão e definindo instrumentos de monitoramento; vii) O poder político deve assumir o papel de motor de arranque, criando vantagens fiscais, infraestruturas, eliminando barreiras físicas e 
jurídicas, atribuindo apoios, etc.; mas deve resistir à tentação de ter o domínio do projeto (O'MARA apud FAUSTINO, 2013, p. 46).

Picard descreve que os clusters se caracterizam por promover interações que necessitam de um contato contínuo que, "[...] muitas vezes, levam a que outras empresas prestadoras de serviços complementares se localizem perto daquelas que, efetivamente necessitem de seus serviços" (PICARD, 2010 apud FAUSTINO, 2013, p. 46-47). O fato dessas empresas estarem próximas geograficamente "[...] e de possuírem um ambiente construído por um conjunto de iniciativas que dinamizam a convivência, a troca de experiências, o compartilhamento de ideias e projetos, dentre outros, propiciam a geração de inovação e de artefatos com alto valor agregado" (SILVA, 2014, p. 82).

Com base nos conceitos apresentados, a formação de um cluster criativo numa determinada cidade pode proporcionar tanto fatores positivos como negativos. Os positivos podem se caracterizar, entre tantos, pela criação de empregos, atração de pessoas com talento, reabilitação de zonas degradadas e a consequente valorização da imagem da cidade. Os fatores negativos, por sua vez, se caracterizam por exemplo, pelo aumento do custo de vida; elevação nos preços dos imóveis; transtornos cotidianos na vida urbana como insegurança, aumento no tráfego, no nível de ruído, etc. Conforme apontado anteriormente, a definição de políticas públicas adequadas e específicas devem, portanto, buscar a medida apropriada para o equilíbrio dessas externalidades.

Fica claro que o entendimento do cluster formatado como arranjo produtivo local, tem grande potencial de conduzir a transformação de um espaço ou de uma região, desempenhando papel fundamental nos processos de regeneração urbana - em diversas escalas e atividades - e consequente desenvolvimento econômico, conforme apontam os dois exemplos a seguir.

A partir da transformação de uma antiga unidade fabril em um novo polo de criatividade na região de Alcântara em Lisboa, Portugal, o cluster 
LxFactory (ttps//www.Ixfactory.com), possui mais de 200 espaços para empreendimentos ligados à criatividade (designers, cientistas, tradutores, programadores, arquitetos, fotógrafos, agentes de marketing, etc.), além de espaços abertos para diversas atividades, cafés e restaurantes, empregando cerca de 1.000 pessoas e atraindo mais de um milhão de visitantes por ano.

Com atuação nos setores de software e serviços de Tecnologia da Informação e Comunicação (TIC) e Economia Criativa (EC), com ênfase nos segmentos de games, multimídia, audiovisual, música, fotografia, design, e mais recentemente, tecnologias urbanas, o Porto Digital (www.portodigital.org), localizado na cidade do Recife-PE, emprega cerca de 8.500 pessoas nas mais de 260 empresas, institutos de pesquisa, incubadoras, aceleradoras e fundos de investimento. Além do reconhecimento por sua atuação como indutor de negócios, a implantação do cluster Porto Digital foi fundamental para a revitalização do Bairro do Recife e de seu patrimônio construído.

O parque tecnológico, por ocupar uma área portuária com edificações históricas, acrescenta como iniciativa ações de revitalização das edificações, com o objetivo de combinar o desenvolvimento tecnológico com a preservação da história e da cultura da cidade, através de uma parceria entre o público e o privado. Nesta direção, foram recuparados diversos edifícios de destaque histórico, correspondendo a mais de 24 mil metros quadrados, passando por uma adequação da infraestrutura do bairro, melhorando os arruamentos, as praças e a infraestrutura tecnológica para receber empresas modernas, mantendo suas características arquitetônicas, que apresentam uma grande diversidade de estilos, mesclando o colonial, o eclético, o industrial e o moderno. 


\section{Considerações finais}

Diante do exposto ao longo deste artigo, um cluster engloba estruturas bem mais complexas do que simplesmente uma concentração de determinados setores em uma localidade específica. Apesar de muitas vezes a sua implantação corresponder a iniciativas isoladas e sem vínculo com planos diretores municipais ou com políticas mais amplas, é possível considerá-lo como alternativa importante para a renovação do território e propulsor da coexistência de certas cidades, constituindo uma nova estratégia produtiva na economia criativa.

Neste estudo buscou-se trazer exemplos que demonstraram a importância dos clusters em agregar valor econômico a áreas degradadas nas cidades, tais como, edifícios fabris e portos em desuso, promovendo a transformação dessas áreas para novas funções e possibilitando seus habitantes explorarem a sua capacidade criativa.

A partir desta iniciativa, os mapas mentais e afetivos são expandidos na população. Reis e Urani (2011, p. 35) explicam que mapas mentais são "representações individuais de uma cidade, variando de pessoa a pessoa, conforme as áreas que the são familiares." Já os afetivos são menores, são os locais da cidade em que o indivíduo além de conhecer, tem uma relação emocional.

\footnotetext{
Ao amar sua cidade, sua população se apropria dela e passa a participar e exigir transformações. Por isso, ampliar os mapas individuais - mentais e afetivos - também é fundamental para reduzir desigualdades sociais no contexto urbano (REIS; URANI, 2011, p. 35).
}

Como consequência, independente da escala, a implantação de um cluster abre possibilidades para criação de uma identidade e de um ambiente criativo. As cidades para se tornarem criativas, devem antes de tudo, procurar e reconhecer a riqueza de seu patrimônio, o seu potencial criativo e o talento das suas pessoas. 


\section{tríade}

Pode-se imaginar a expansão criativa que a cidade obteria se fosse realizado um investimento massivo num sistema de ensino e profissionalização avançado, com adequação curricular a novas profissões dos setores criativos; em políticas públicas de longo alcance voltadas a economia criativa; em políticas de desenvolvimento social; na preservação de seu patrimônio histórico e cultural; num sistema de transporte público integrado; entre tantos outros fatores fomentadores do desenvolvimento.

Várias cidades apresentam vantagens competitivas evidentes nas indústrias criativas; talentos diversificados e voltados à produção de conhecimento; eventos locais e nacionais; oferta cultural e de equipamentos culturais; além de concentrar profissionalismo e dinamismo em seus circuitos comerciais, serviços de excelência, polos tecnológicos e culturais. Estas cidades podem então tornar-se criativas quando lançadas as condições necessárias à formação de um ambiente favorável a seus setores criativos ao se valer de políticas públicas estruturadoras, complementadas pelo reconhecimento dado aos vários valores de sua criatividade e ao de sua gente.

Por fim, este artigo buscou contribuir na discussão sobre a relação de coexistência entre a sociedade e as indústrias criativas no contexto urbano, decorrente da implantação de clusters criativos, que podem fornecer novos caminhos para o aperfeiçoamento de análises que visem ao desenvolvimento das cidades sob o enfoque criativo entre outros que podem surgir pela amplitude do tema. 


\section{Referências}

CASTELLS, M. O poder da comunicação. São Paulo: Paz e Terra, 2009.

FALCÃO, C. et al. O papel do Cluster Criativo na reabilitação urbana: o Bairro do Recife e o Porto Digital. In: LINS, A. M. G. (Org.). Mídia e cultura contemporânea: série linguagem, volume 3. Porto Alegre, RS: Editora Fi, 2018. p. 71-85.

FAUSTINO, P. Indústrias criativas, media e clusters. Lisboa: Media XXI, 2013.

FLORIDA, R. The rise of the creative class. New York: Basic Books, 2002.

LANDRY, C. Origens e futuros da cidade criativa. São Paulo: SESI-SP Editora, 2013.

LANDRY, C. The creative city: a toolkit for urban innovators. London: Earthscan, 2008.

LEITE, C., AWAD, J. Cidades sustentáveis, cidades inteligentes: desenvolvimento sustentável num planeta urbano. Porto Alegre: Bookman, 2012.

PARDO, J. Gestão e governança nas cidades criativas. In: REIS, A; KAGEYAMA, P (orgs). Cidades criativas: perspectivas. São Paulo: Garimpo de Soluções, 2011. p. 84-93.

PORTER, M. Clusters and the new economics of competition. Rio de Janeiro: Harvard Business Review, 1998.

REIS, A.C.F.: Cidades criativas - análise de um conceito em formação e da pertinência de sua aplicação à cidade de São Paulo. 312 f. Tese (Doutorado em Arquitetura) - Faculdade de Arquitetura e Urbanismo da Universidade de São Paulo, São Paulo, 2011.

REIS, A. ; URANI, A. Cidades criativas: perspectivas brasileiras. In: REIS, A; KAGEYAMA, P (orgs). Cidades criativas: perspectivas. São Paulo: Garimpo de Soluções, 2011. p. 30-37.

SILVA, Anderson D. F. da. O processo regulador na (re)conversão de um arranjo produtivo local: o caso do Portomídia - Centro de Empreendedorismo e Tecnologia da Economia Criativa. Dissertação 


\section{tríade}

(Mestrado em Administração) - Universidade Federal de Pernambuco, Recife, 2014.

SILVEIRA, S; BENKLER, Y. et al. Comunicação digital e a construção dos commons: redes virais, espectro aberto e as novas possibilidades de regulação. São Paulo: Editora Fundação Perseu Abramo, 2007.

SPOSITO, M. E. B. Capitalismo e urbanização. São Paulo: Contexto, 1988.

UNESCO. Guidelines on Intercultural Education. 2006. Disponível em: http://unesdoc.unesco.org/images/0014/001478/147878e.pdf. Acesso em: 14 nov. 2018. 